\title{
Penyelesaian Numerik Advection Equation 1 Dimensi dengan EFG-DGM
}

\author{
Kresno Wikan Sadono \\ Departemen Teknik Sipil, Fakultas Teknik, Universitas Diponegoro \\ Jl. Prof. Soedarto, SH, Tembalang, Semarang 50275 \\ E-mail: kresnowikan@gmail.com
}

\begin{abstract}
Differential equation can be used to model various phenomena in science and engineering. Numerical method is the most common method used in solving DE. Numerical methods that popular today are finite difference method (FDM), finite element method (FEM) dan discontinuous Galerkin method (DGM), which the method includes mesh based. Lately, the developing methods, that are not based on a mesh, which the nodes directly spread in domain, called meshfree or meshless. Element free Galerkin method (EFG), PetrovGalerkin meshless (MLPG), reproducing kernel particle method (RKPM) and radial basis function (RBF) fall into the category meshless or meshfree. Time integration generally use an explicit Runge Kutta 4th order, Newmark- $\beta$, HHT- $\alpha$, Wilson- $\theta$ dll. This research was carried out numerical simulations DE, by combining the EFG method to solve the domain space and time integration with DGM methods. EFG using the complete order polynomial 1, and DGM used polynomial order 1. The equation used advection equation in one dimension. EFG-DGM comparison with analytical results also performed. The simulation results show the method EFG-DGM match the one-dimensional advection equations well.
\end{abstract}

Keywords: Differential equations, Numerical method, Finite element method, Discontinuous Galerkin method, Element free Galerkin method, Time integration, Advection equation.

\begin{abstract}
Abstrak
Persamaan differensial atau differential equation DE, dapat digunakan untuk memodelkan berbagai fenomena dalam bidang sains dan rekayasa. Metode numerik adalah metode yang paling umum digunakan dalam penyelesaian DE. Metode numerik yang populer saat ini adalah metode beda hingga atau finite difference method (FDM), finite element method (FEM) dan discontinuous Galerkin method (DGM), dimana metode ini termasuk mesh based. Akhir-akhir ini berkembang metode yang tidak berbasis pada mesh, dimana node langsung disebar pada domain, disebut meshfree atau meshless. Metode element free Galerkin method (EFG), meshless Petrov-Galerkin (MLPG), reproducing kernel particle method (RKPM) dan radial basis function $(R B F)$ masuk dalam kategori meshless. Integrasi waktu atau time integration yang digunakan umumnya menggunakan explicit Runge Kutta 4th order, Newmark- $\beta$, HHT- $\alpha$, Wilson- $\theta$ dll. Pada penelitian ini dilakukan simulasi numerik penyelesaian DE, dengan menggabungkan metode EFG untuk penyelesaian domain ruang dan integrasi waktu dengan metode DGM. Simulasi EFG menggunakan complete polynomial orde 1 dan DGM digunakan polynomial orde 1. Persamaan yang digunakan adalah advection atau advection equation pada satu dimensi. Perbandingan EFG-DGM dengan hasil analitis atau exact dilakukan. Hasil simulasi menunjukkan metode EFG-DGM dapat mendekati persamaan advection satu dimensi dengan baik.
\end{abstract}

Kata-kata kunci: Persamaan differensial, Metode numerik, Finite element method, Discontinuous Galerkin method, Element free Galerkin method, Time integration, Advection equation.

\section{Pendahuluan}

Pada bidang sains dan rekayasa, persamaan differensial atau differential equation (DE) merupakan persamaan matematika yang digunakan untuk memodelkan berbagai fenomena dalam bidang sains dan rekayasa. Penyelesaian DE untuk kepentingan pemodelan dengan menggunakan metode analitis tersedia hanya untuk masalah yang sederhana. Untuk aplikasi dalam sains dan rekayasa, metode numerik, merupakan metode yang paling umum digunakan menyelesaikan DE. Metode numerik yang paling populer untuk 
menyelesaikan DE dan populer digunakan untuk berbagai masalah adalah metode beda hingga atau finite difference method (FDM), metode elemen hingga atau finite element method (FEM) dan discontinuous Galerkin method (DGM). Metode FDM dan FEM adalah metode yang berbasis pada mesh pada domain. Dimana domain dibagi menjadi subdomain yang lebih kecil yang disebut elemen.

Metode FDM merupakan metode paling awal yang digunakan untuk menyelesaikan simulasi DE. Metode FDM masih digunakan untuk simulasi DE hingga saat ini karena kemudahannya dan kesederhanaannya. Terlepas dari kemudahannya, metode FDM kesulitan untuk penyelesaian DE dengan kondisi domain dan boundary yang rumit.

Metode FEM populer setelah FDM, metode FEM dapat melakukan simulasi pada domain yang rumit. Metode FEM dengan berbagai variasinya dapat digunakan untuk simulasi medium solid dan fluida pada bidang sains dan rekayasa. Salah satu variasi dari metode FEM adalah discontinuous Galerkin method (DGM), metode ini dapat digunakan untuk solusi pada domain yang tidak kontinyu (Hesthaven \& Warburton, 2008) dan (Li BQ, 2006).

Untuk beberapa kondisi, metode numerik berbasis pada mesh umumnya tidak efisien, lebih rumit dan menyita waktu, karena memerlukan mesh dari domain (Belytschko et al., 1994). Sehingga akhirakhir ini, metode numerik selain berbasis mesh seperti FDM dan FEM, dikembangkan untuk menyelesaikan DE. Metode ini dapat menyelesaikan DE tanpa membagi domain menjadi subdomain. Metode ini memiliki keunggulan dengan menyebarkan node pada domain dan boundary, metode ini disebut dengan meshfree atau meshless. Metode yang termasuk kategori meshless adalah element free Galerkin method (EFG), meshless Petrov-Galerkin (MLPG), reproducing kernel particle method (RKPM) dan radial basis function (RBF).

Pada umumnya penggunaan metode mesh based maupun meshless memerlukan kombinasi dengan integrasi waktu atau time integration. Integrasi waktu dilakukan untuk melakukan simulasi pada domain waktu, dimana simulasi pada domain waktu pada umumnya menggunakan metode explicit Runge Kutta 4th order, Newmark- $\beta$, HHT$\alpha$, Wilson- $\theta$ dll, (Bathe, 1996).

Pada penelitian kali ini akan dilakukan penyelesaiaan secara numerik pada persamaan advection pada satu dimensi, dengan penggabungan metode EFG untuk menyelesaikan domain ruang, dan integrasi waktu dengan DGM. Pemilihan metode EFG karena metode ini merupakan meshles sehingga lebih mudah tanpa melakukan mesh pada domain dan hanya menyebar node. Integrasi dilakukan dengan DGM dengan alasan metode tersebut termasuk metode implisit sehingga akurat dan stabil. Diharapkan dengan penggabungan metode EFG-DGM, dihasilkan penyelesaian numerik yang lebih sederhana dan lebih akurat. Pada penelitian kali ini metode EFG-DGM diaplikasikan pada persamaan advection pada satu dimensi. Persamaan advection digunakan karena kesederhanaan tersedia solusi analitisnya atau exactnya.

\section{Metode Penelitian}

Persamaan deferensial parsial (partial differential equation, PDE) tipe adveksi (advection equations) yang diselesaikan secara numerik ditampilkan pada Persamaan 1 (Sara dan Kansa, 2010).

$\frac{\partial u(x, t)}{\partial t}-\frac{\partial u(x, t)}{\partial x}=0$

$x_{l} \leq x \leq x_{r}$

$t>0$

Dengan boundary condition (BC) dan initial condition (IC) dinyatakan pada Persamaan 2, (Sara dan Kansa, 2010).

$u(1, t)=0$ dan

$u(x, 0)=\exp \left(-40(x-0.4)^{2}\right.$

Solusi analitik atau exact solution dari Persamaan 1 dan Persamaan 2 dinyatakan dalam Persamaan 3, (Sara dan Kansa, 2010).

$u(x, t)=\exp \left(-40(x-0.4+t)^{2}\right)$

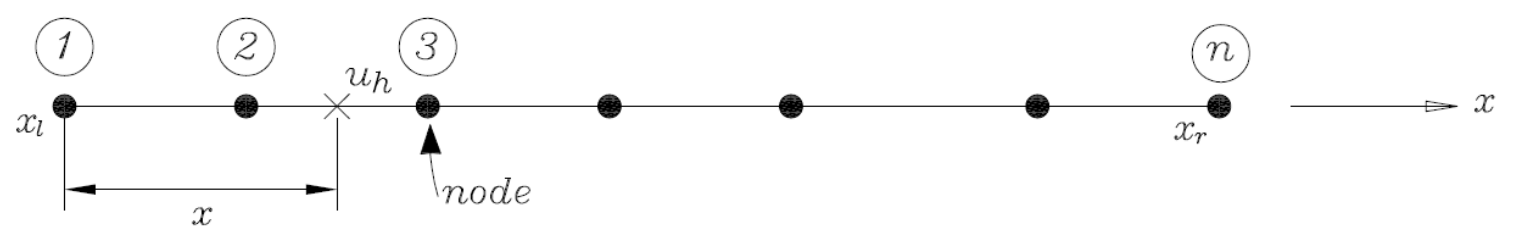

Gambar 1. Sebaran node untuk domain ruang $x_{l} \leq x \leq x_{r}$ 
Persamaan 1 diselesaikan dengan element free Galerkin (EFG) pada domain ruang dan diselesaikan dengan Discontinuous Galerkin Method (DGM) pada domain waktu, sehingga solusi ini dinamakan EFG-DGM. Jika domain ruang pada Persamaan 1 yakni $x_{l} \leq x \leq x_{r}$ disebar sesuai node pada Gambar 1. Maka MLS approximant pada suatu lokasi $x$ dapat diketahui, dari $u_{h}$ dinyatakan dalam Persamaan 4, (Belytschko et al., 1994).

$u_{h}=\sum_{I=1}^{n} \Phi_{I}(x) u_{I}=\boldsymbol{\Phi}(x) \mathbf{u}$

Indeks $I$ untuk tiap node dari $n$ jumlah node pada neigborhood dari $x$. Nilai $u_{I}$ adalah nilai unknown pada node ke $I$. Sedangkan nilai dari $\Phi_{I}(x)$ adalah shape function dari MLS approximants dinyatakan pada Persamaan 5, (Belytschko et al., 1994).

Matrix A memiliki komponen $(m+1) \times(m+1)$, dimana $m$ adalah orde dari complete polynomial pada matrix $\mathbf{p}$ yang dinyatakan pada Persamaan 9, dimana polynomial order dinyatakan dengan $r$. Matrix A pada Persamaan 8, memiliki elemen $2 \times 2$ dengan complete polynomial orde 1 dari matrix p dinyatakan pada Persamaan 10, dimana nilai dari B pada Persamaan 5 dinyatakan pada Persamaan 11.
Persamaan advection diselesaikan dengan EFG, yakni dengan mengalikan persamaan advection dengan test function yang sama dengan shape function $\Phi_{I}$ dan melakukan integrasi pada domain ruang $\Omega$ yakni $x_{l} \leq x \leq x_{r}$. Proses integrasi dilakukan dengan bantuan background mesh. Background mesh yakni mesh bantuan yang digunakan untuk melakukan perhitungan integrasi numerik. Pada background mesh terdapat gauss point dimana perhitungan integrasi dilakukan. Sehingga perhitungan integrasi dilakukan untuk tiap background mesh.

Sehingga untuk persamaan advection maka integrasi dilakukan pada background mesh pada $\Omega_{p}$, dimana background mesh berjumlah $L$ buah, yang ditampilkan pada Persamaan 14. Integrasi dilakukan dengan menggunakan gauss point pada background mesh. Penjelasan dari background mesh ditampilkan pada Gambar 2.

Pendekatan pada nilai $u(x, t)$ menggunakan Persamaan 4. Dengan mensubstitusikan Persamaan 4, ke Persamaan 14, maka menghasilkan Persamaan 15 , dimana $\Phi_{J}=\Phi_{1}, \Phi_{2}, \ldots, \Phi_{n}$ atau menghasilkan Persamaan 16.

$\Phi_{I}(x)=\sum_{j=0}^{m} p_{j}(x)\left(\mathbf{A}^{-\mathbf{1}}(x) \mathbf{B}(x)\right)_{j I}=\mathbf{p}^{T} \mathbf{A}^{-\mathbf{1}}(x) \mathbf{B}_{I}(x)$

Nilai A dinyatakan dalam Persamaan 6.

$\mathbf{A}=\sum_{I=1}^{n} w\left(x-x_{I}\right) \mathbf{p}\left(x_{I}\right) \mathbf{p}^{T}\left(x_{I}\right)$

$\mathbf{A}=w\left(x-x_{1}\right)\left(\begin{array}{c}1 \\ x_{1}\end{array}\right)\left(\begin{array}{ll}1 & x_{1}\end{array}\right)+w\left(x-x_{2}\right)\left(\begin{array}{c}1 \\ x_{2}\end{array}\right)\left(\begin{array}{ll}1 & x_{2}\end{array}\right)+\cdots+w\left(x-x_{n}\right)\left(\begin{array}{c}1 \\ x_{n}\end{array}\right)\left(\begin{array}{ll}1 & x_{n}\end{array}\right)$

$\mathbf{A}=w\left(x-x_{1}\right)\left(\begin{array}{cc}1 & x_{1} \\ x_{1} & x_{1}^{2}\end{array}\right)+w\left(x-x_{2}\right)\left(\begin{array}{cc}1 & x_{2} \\ x_{2} & x_{2}^{2}\end{array}\right)+\cdots+w\left(x-x_{n}\right)\left(\begin{array}{cc}1 & x_{n} \\ x_{n} & x_{n}^{2}\end{array}\right)$

$\mathbf{p}^{\mathbf{T}}(\mathbf{x})=\left(\begin{array}{lllll}\mathbf{1} & \mathbf{x} & \mathbf{x}^{2} & \cdots & \mathbf{x}^{\mathbf{r}}\end{array}\right)$

$\mathbf{p}^{\mathbf{T}}(x)=(1 x)$

$\mathrm{B}=\left(\begin{array}{llll}\mathrm{w}\left(\mathrm{x}-\mathrm{x}_{1}\right) \mathrm{p}\left(\mathrm{x}_{1}\right) & \left.\mathrm{w}\left(\mathrm{x}-\mathrm{x}_{2}\right) \mathrm{p}\left(\mathrm{x}_{2}\right) \quad \ldots \quad \mathrm{w}\left(\mathrm{x}-\mathrm{x}_{\mathrm{n}}\right) \mathrm{p}\left(\mathrm{x}_{\mathrm{n}}\right)\right)\end{array}\right.$

$\mathrm{B}=\left(\mathrm{w}\left(\mathrm{x}-\mathrm{x}_{1}\right)\left(\begin{array}{c}1 \\ \mathrm{x}_{1}\end{array}\right) \quad \mathrm{w}\left(\mathrm{x}-\mathrm{x}_{2}\right)\left(\begin{array}{c}1 \\ \mathrm{x}_{2}\end{array}\right) \quad \ldots \quad w\left(x-x_{n}\right)\left(\begin{array}{c}1 \\ \mathrm{x}_{\mathrm{n}}\end{array}\right)\right)$

$\mathrm{B}=\left(\begin{array}{cccc}w\left(x-x_{1}\right) & w\left(x-x_{2}\right) & & w\left(x-x_{n}\right) \\ & & \ldots & \\ x_{1} w\left(x-x_{1}\right) & x_{2} w\left(x-x_{2}\right) & & x_{n} w\left(x-x_{n}\right)\end{array}\right)$

$\sum_{\mathrm{p}=1}^{\mathrm{L}}\left[\int_{\Omega_{\mathrm{p}}}\left(\Phi_{\mathrm{I}} \frac{\partial \mathrm{u}_{\mathrm{h}}}{\partial \mathrm{t}}-\Phi_{\mathrm{I}} \frac{\partial \mathrm{u}_{\mathrm{h}}}{\partial \mathrm{x}}\right) \mathrm{dx}\right]=0$

for $\Phi_{\mathrm{I}}=\Phi_{1}, \Phi_{2}, \ldots, \Phi_{\mathrm{n}}$

$\sum_{\mathrm{p}=1}^{\mathrm{L}}\left[\int_{\Omega_{\mathrm{p}}}\left(\Phi_{\mathrm{J}}(\mathrm{x}) \frac{\partial}{\partial \mathrm{t}}\left(\sum_{\mathrm{I}=1}^{\mathrm{n}} \Phi_{\mathrm{I}}(\mathrm{x}) \mathrm{u}_{\mathrm{I}}\right)-\Phi_{\mathrm{J}}(\mathrm{x}) \frac{\partial}{\partial \mathrm{x}}\left(\sum_{\mathrm{I}=1}^{\mathrm{n}} \Phi_{\mathrm{I}}(\mathrm{x}) \mathrm{u}_{\mathrm{I}}\right)\right) \mathrm{dx}\right]=0$ 


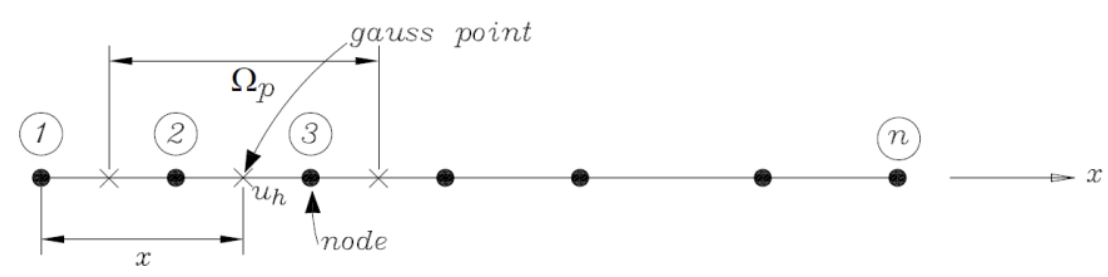

Gambar 2. Background mesh pada $\Omega_{p}$

$\sum_{p=1}^{L}\left[\int_{\Omega_{p}}\left(\left(\sum_{I=1}^{n} \Phi_{I} \Phi_{J} \frac{\partial u_{I}}{\partial t}\right)-\left(\sum_{I=1}^{n} \Phi_{J} \frac{\partial \Phi_{I}}{\partial x} u_{I}=\right)\right) \mathrm{d} x\right]=0$

Persamaan 16 dapat dinyatakan dalam Persamaan 17.

$\sum_{p=1}^{L}\left[\int_{\Omega_{p}}\left(\begin{array}{c}\Phi_{1} \\ \Phi_{2} \\ \vdots \\ \Phi_{n}\end{array}\right)\left(\begin{array}{llll}\Phi_{1} & \Phi_{2} & \cdots & \Phi_{n}\end{array}\right) \mathrm{d} x\left(\begin{array}{c}\frac{\partial u_{1}}{\partial t} \\ \frac{\partial u_{2}}{\partial t} \\ \vdots \\ \frac{\partial u_{n}}{\partial t}\end{array}\right)\right]-\sum_{p=1}^{L}\left[\int_{\Omega_{p}}\left(\begin{array}{c}\Phi_{1} \\ \Phi_{2} \\ \vdots \\ \Phi_{n}\end{array}\right)\left(\begin{array}{llll}\frac{\partial \Phi_{1}}{\partial x} & \frac{\partial \Phi_{2}}{\partial x} & \cdots & \frac{\partial \Phi_{n}}{\partial x}\end{array}\right) \mathrm{d} x\left(\begin{array}{c}u_{1} \\ u_{2} \\ \vdots \\ u_{n}\end{array}\right)\right]=0$

Persamaan 17 dapat dinyatakan dalam bentuk matix sesuai dengan Persamaan 18.

$\mathrm{C} \frac{\partial \mathrm{u}}{\partial t}-\mathrm{Ku}=0$

dimana

$\mathrm{C}=\sum_{p=1}^{L}\left[\int_{\Omega_{p}}\left(\begin{array}{c}\Phi_{1} \\ \Phi_{2} \\ \vdots \\ \Phi_{n}\end{array}\right)\left(\begin{array}{llll}\Phi_{1} & \Phi_{2} & \ldots & \Phi_{n}\end{array}\right) \mathrm{d} x\right]=\sum_{p=1}^{L}\left[\int_{\Omega_{p}}\left(\begin{array}{cccc}\Phi_{1} \Phi_{1} & \Phi_{1} \Phi_{2} & \ldots & \Phi_{1} \Phi_{n} \\ \Phi_{2} \Phi_{1} & \Phi_{2} \Phi_{2} & \ldots & \Phi_{2} \Phi_{n} \\ \vdots & \vdots & \ddots & \vdots \\ \Phi_{n} \Phi_{1} & \Phi_{n} \Phi_{2} & \ldots & \Phi_{n} \Phi_{n}\end{array}\right)\right]$

$\mathrm{K}=\sum_{p=1}^{L}\left[\int_{\Omega_{p}}\left(\begin{array}{c}\Phi_{1} \\ \Phi_{2} \\ \vdots \\ \Phi_{n}\end{array}\right)\left(\begin{array}{llll}\frac{\partial \Phi_{1}}{\partial x} & \frac{\partial \Phi_{2}}{\partial x} & \ldots & \frac{\partial \Phi_{n}}{\partial x}\end{array}\right) \mathrm{d} x\right]=\sum_{p=1}^{L}\left[\int_{\Omega_{p}}\left(\begin{array}{cccc}\Phi_{1} \frac{\partial \Phi_{1}}{\partial x} & \Phi_{1} \frac{\partial \Phi_{2}}{\partial x} & \ldots & \Phi_{1} \frac{\partial \Phi_{n}}{\partial x} \\ \Phi_{2} \frac{\partial \Phi_{1}}{\partial x} & \Phi_{2} \frac{\partial \Phi_{2}}{\partial x} & \ldots & \Phi_{2} \frac{\partial \Phi_{n}}{\partial x} \\ \vdots & \vdots & \ddots & \vdots \\ \Phi_{n} \frac{\partial \Phi_{1}}{\partial x} & \Phi_{n} \frac{\partial \Phi_{2}}{\partial x} & \ldots & \Phi_{n} \frac{\partial \Phi_{n}}{\partial x}\end{array}\right)\right]$

$\frac{\partial \mathrm{u}}{\partial \mathrm{t}}=\left(\begin{array}{c}\frac{\partial u_{1}}{\partial t} \\ \frac{\partial u_{2}}{\partial t} \\ \vdots \\ \frac{\partial u_{n}}{\partial t}\end{array}\right) \quad ; \quad \mathrm{u}=\left(\begin{array}{c}u_{1} \\ u_{2} \\ \vdots \\ u_{n}\end{array}\right)$

Persamaan 18 berupa ordinary differential equation (ODE), dihasilkan dari Persamaan 1 berupa PDE dengan EFG. Setelah berubah menjadi ODE, diselesaikan dengan DGM, penyelesaian seperti dengan mengkonversi PDE menjadi ODE, disebut partial discretization (Zienkiewicz \& Morgan, 1982). Persamaan 18 diselesaikan dengan integrasi waktu dengan DGM. Dengan membagi time domain menjadi subinterval $I_{k}=\left[t_{k}, t_{k+1}\right]$, dimana $l=0,1, \ldots, L-1$. Dengan mengalikan Persamaan 18 dengan weight function $w$, dan melakukan integrasi pada subinterval $I_{k}$, maka menghasilkan Persamaan 22.

$\int_{t_{k}}^{t_{k+1}}\left(\mathrm{C} \frac{\mathrm{du}}{\mathrm{d} t}-\mathrm{Ku}\right) w_{l}(t) \mathrm{d} t=0$

Nilai $\mathbf{u}(t)$ didekati $\widehat{\mathbf{u}}(t(\xi))$ dengan Persamaan 23. $\widehat{\mathbf{u}}(t(\xi))=\mathbf{u}_{k}^{+} \psi_{1}(\xi)+\mathbf{u}_{k+1}^{-} \psi_{2}(\xi)$

Dengan shape function $\psi_{1}$ dan $\psi_{2}$ dinyatakan pada Persamaan 24, (Zienkiewicz \& Morgan, 1982).

$\boldsymbol{\Psi}_{1}(\xi)=\frac{1}{2}(1-\xi) ; \boldsymbol{\Psi}_{2}(\xi)=\frac{1}{2}(1+\xi)$

Persamaan 23 mendekati $\mathbf{u}(t)$ dengan $\widehat{\mathbf{u}}(t(\xi))$ pada Persamaan 23. Dimana memerlukan transformasi koordinat ke natural coordinate $(\xi)$, yang dinyatakan pada Persamaan 25 .

$t(\xi)=\frac{1}{2}\left(t_{n}+t_{n+1}\right)+\frac{1}{2} \xi\left(t_{n+1}-t_{n}\right)$

Dimana turunan Persamaan 25 dinyatakan pada Persamaan 26.

$\mathrm{d} t=\frac{\Delta t}{2} \mathrm{~d} \xi=\frac{\left(t_{k+1}-t_{k}\right)}{2} \mathrm{~d} \xi$ 


$$
\begin{aligned}
& \mathbf{C u}^{+}\left(t_{k}\right) \psi_{l}\left(t_{k}\right)-\mathbf{C u}^{-}\left(t_{k}\right) \psi_{l}\left(t_{k}\right)+\int_{t_{k}}^{t_{k+1}} \psi_{l} \mathbf{C} \frac{\mathrm{d} \widehat{u}}{\mathrm{~d} t}-\mathbf{K} \widehat{\mathbf{u}} \psi_{l} \mathrm{~d} t=0 \\
& \mathbf{C u}^{+}\left(t_{k}\right) \psi_{1}\left(t_{k}\right)-\mathbf{C u}^{-}\left(t_{k}\right) \psi_{1}\left(t_{k}\right)+ \\
& \int_{-1}^{+1}\left[\psi_{1} \mathbf{C} \frac{\mathrm{d}}{\mathrm{d} t}\left(\mathbf{u}_{k}^{+} \psi_{1}+\mathbf{u}_{k+1}^{-} \psi_{2}\right)-\mathbf{K}\left(\mathbf{u}_{k}^{+} \psi_{1}+\mathbf{u}_{k+1}^{-} \psi_{2}\right) \psi_{1} \frac{\left(t_{k+1}-t_{k}\right)}{2}\right] \mathrm{d} \xi=0 .
\end{aligned}
$$

Dengan menyelesaikan Persamaan 28 maka menghasilkan Persamaan 29.

$-\frac{1}{2} \mathbf{C u}_{\mathrm{k}}^{+}+\frac{1}{2} \mathrm{Cu}_{\mathrm{k}+1}^{+}-\frac{1}{6} \Delta \mathrm{tKu} \mathbf{k}_{\mathrm{k}}^{+}-\frac{1}{3} \Delta \mathrm{tKu} \mathbf{k}+1_{-}^{-}=0$

Dengan cara yang sama dengan diatas, dengan memasukkan Persamaan 23, 24 ke Persamaan 27 dengan $\psi_{l}=\psi_{2}$ maka menghasilkan Persamaan 30

$$
\begin{aligned}
& \mathbf{C u}^{+}\left(t_{k}\right) \psi_{2}\left(t_{k}\right)-\mathbf{C u}^{-}\left(t_{k}\right) \psi_{2}\left(t_{k}\right)+ \\
& \int_{-1}^{+1}\left[\psi_{2} \mathbf{C} \frac{\mathrm{d}}{\mathrm{d} t}\left(\mathbf{u}_{k}^{+} \psi_{1}+\mathbf{u}_{k+1}^{-} \psi_{2}\right)-\psi_{2} \mathbf{K}\left(\mathbf{u}_{k}^{+} \psi_{1}+\mathbf{u}_{k+1}^{-} \psi_{2}\right) \frac{\left(t_{k+1}-t_{k}\right)}{2}\right] \mathrm{d} \xi=0
\end{aligned}
$$

Dengan menyelesaikan Persamaan 30, maka menghasilkan Persamaan 31.

$-\frac{1}{2} \mathbf{C} \mathbf{u}_{k}^{+}+\frac{1}{2} \mathbf{C} \mathbf{u}_{k+1}^{-}-\frac{1}{6} \Delta t \mathbf{K} \mathbf{u}_{k}^{+}-\frac{1}{3} \Delta t \mathbf{K} \mathbf{u}_{k+1}^{-}=0$.

Persamaan 22 dilakukan integration by parts dua kali, dan menset test function atau weigh function sama dengan shape function, (BQ Li, 2006). Dimana $w_{l}(t)=\psi_{l}$, dimana $l=1,2$ sehingga Persamaan 22 menjadi Persamaan 27.

Dengan memasukkan Persamaan 23, 24 ke Persamaan 27 dan menentukan $\psi_{l}=\psi_{1}$ maka menghasilkan Persamaan 28.

Dengan menggabungkan Persamaan 29 dan Persamaan 31 dapat dibentuk matriks sesuai Persamaan 32.

Persamaan 32 adalah bentuk akhir penyelesaian numerik dari EFG-DGM. Penyelesaian dilakukan dengan inversi sistem matrik pada suku pertama Persamaan 32, untuk mendapatkan nilai $\mathbf{u}_{k+1}^{-}$.

Pada Persamaan 32, untuk tiap langkah penyelesaian, sisi kanan merupakan suku yang diketahui, baik dari initial condition atau diketahui dari perhitungan sebelumnya.

\section{Pengujian numerik dan hasil}

Pengujian numerik dilakukan pada domain 1 dimensi. Pada sumbu $x$, dengan domain $x_{l} \leq x \leq$ $x_{r}$ dimana $x_{l}=-1,2$ dan $x_{r}=1,2$, disebar jumlah node tertentu dan time increment $(\Delta t)$. Waktu awal $t_{0}=0.0$ dan waktu akhir $t_{f}=1,0$. Simulasi dilakukan dengan 3 macam variasi jumlah node, 25 node (distance between node $\Delta x=0,1$ ); 241

$$
\left(\begin{array}{cc}
\frac{1}{2} \mathbf{C}-\frac{1}{3} \Delta t \mathbf{H} & \frac{1}{2} \mathbf{C}-\frac{1}{6} \Delta t \mathbf{H} \\
-\frac{1}{2} \mathbf{C}-\frac{1}{6} \Delta t \mathbf{H} & \frac{1}{2} \mathbf{C}-\frac{1}{3} \Delta t \mathbf{H}
\end{array}\right)\left(\begin{array}{c}
\mathbf{u}_{k}^{+} \\
\\
\mathbf{u}_{k+1}^{-}
\end{array}\right)=\left(\begin{array}{c}
\mathbf{C} \mathbf{u}_{k}^{-} \\
\\
0
\end{array}\right)
$$

node $(\Delta x=0,01)$ dan 481 node $(\Delta x=0,005)$. Untuk integrasi waktu dengan DGM, digunakan tiga variasi time increment $\Delta t=0,1, \Delta t=0,01$ dan $\Delta t=0,001$

Hasil simulasi untuk $\Delta x=0,1$ dan $\Delta t=0,1$ pada $t_{f}=1,0$ ditampilkan pada Gambar 3, dan tampak simulasi EFG-DGM dibandingkan dengan hasil exact. Untuk meningkatkan akurasi EFG dan DGM dilakukan simulasi dengan memperbanyak jumlah node dan mengurangi time increment $\Delta t$. Hasil simulasi EFG-DGM untuk $\Delta x=0,01$ dan $\Delta t=0,1$ pada $t_{f}=1,0$ ditampilkan pada Gambar 4. Hasil simulasi EFG-DGM untuk $\Delta x=0,01$ dan $\Delta t=0,01$ pada $t=t_{f}=1,0$ ditampilkan pada Gambar 5. Tampak pada Gambar 3, 4 dan 5 dengan semakin memperbanyak jumlah node dan semakin memperkecil time increment maka menghasilkan hasil numerik EFG-DGM yang lebih akurat.

Perbedaan antara hasil exact dan numerik EFGDGM dinyatakan dalam error $=u_{\text {exact }}-$ $u_{\text {EFG-DGM }}$. Hasil $\log _{10} \|$ error $\left\|_{2}=\log _{10}\right\| u_{\text {exact }}-$ $u_{\mathrm{EFG}-\mathrm{DGM}} \|_{2}$ untuk $\Delta x=0,1$ dan $\Delta t=0,1$ pada domain ruang, pada akhir simulasi $\left(t_{f}=t=1,0\right)$ ditampilkan pada Gambar 6, untuk $\Delta x=0,01$ dan $\Delta t=0,01$ ditampilkan Gambar 7 dan untuk $\Delta x=0,01$ dan $\Delta t=0,01$. Dari Gambar 3, 4 dan 5 , semakin meningkatnya jumlah node dan semakin kecilnya time increment maka semakin meningkatnya akurasi EFG-DGM. 


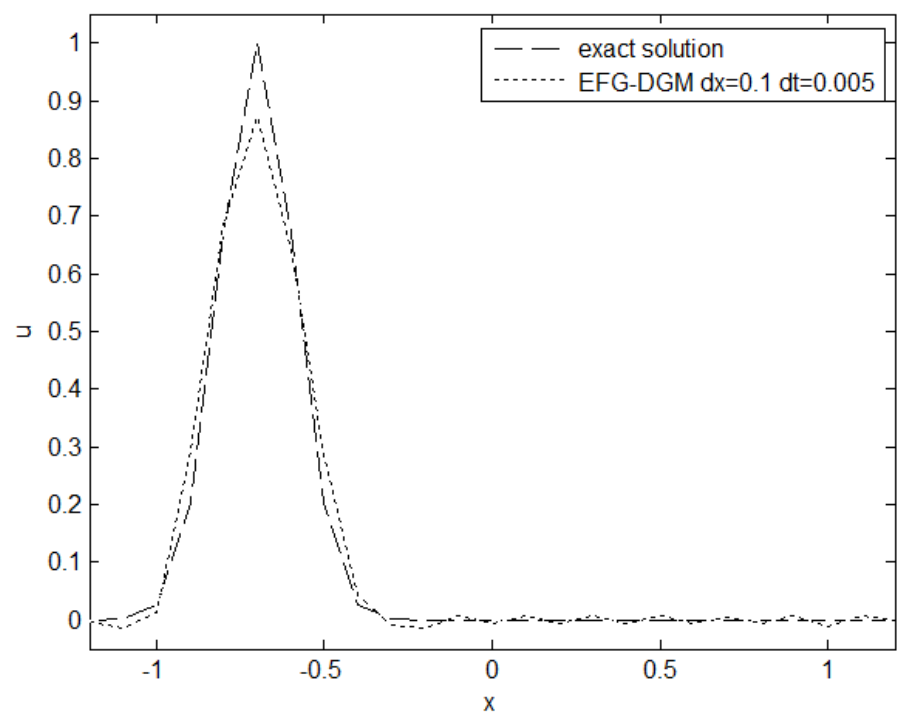

Gambar 3. Hasil simulasi numerik EFG-DGM terhadap exact untuk $\Delta x=0,1, \Delta t=0,1$ pada $t=1,0$

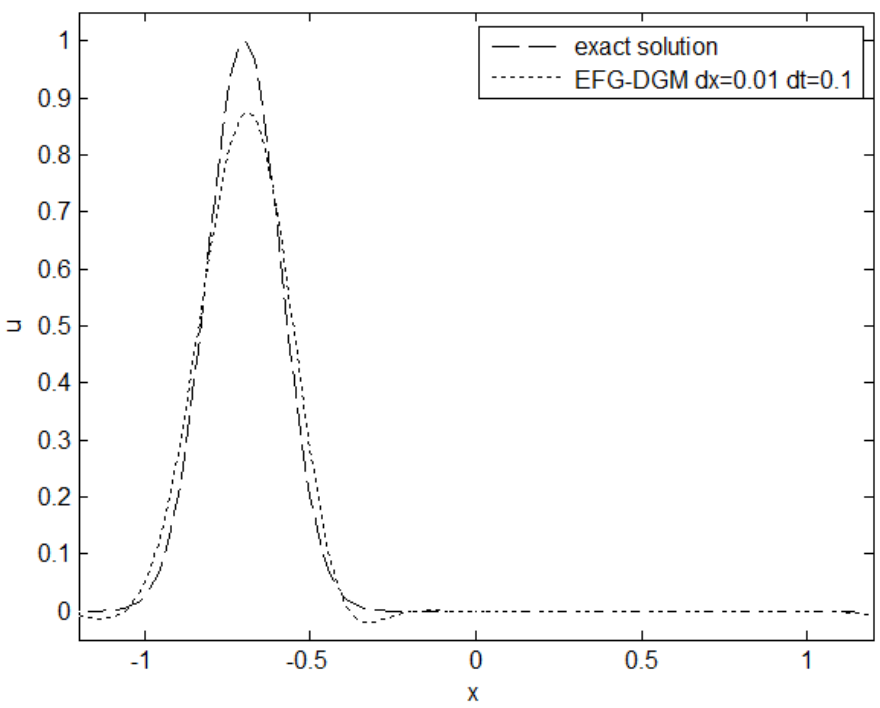

Gambar 4. Hasil simulasi numerik EFG-DGM terhadap exact untuk $\Delta x=0,01, \Delta t=0,1$ pada $t=1,0$

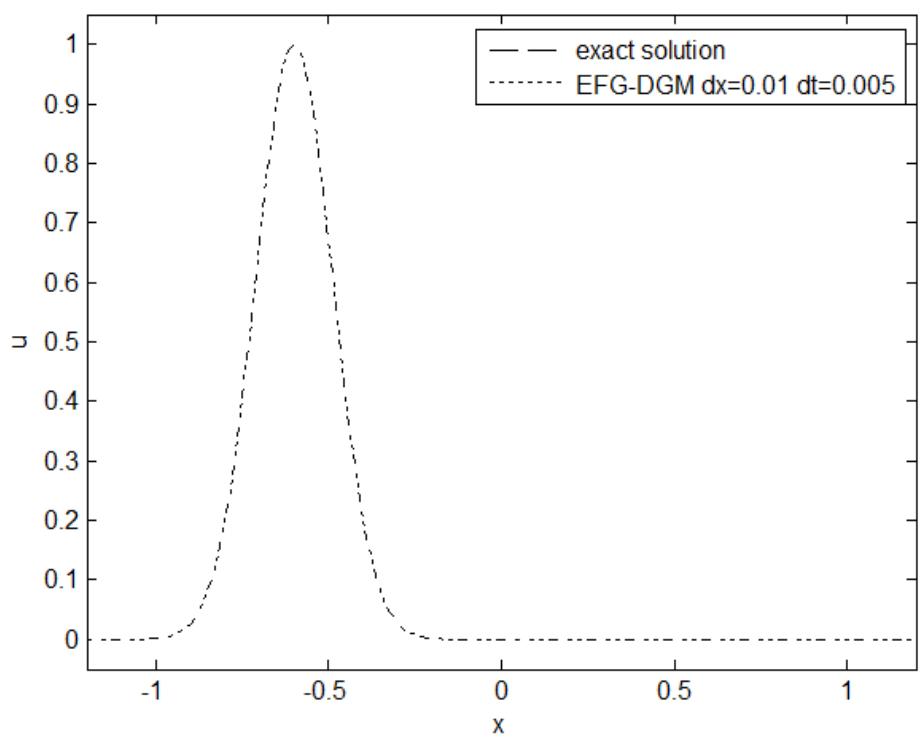

Gambar 5. Hasil simulasi numerik EFG-DGM terhadap exact untuk $\Delta x=0,01, \Delta t=0,005$ pada $t=1,0$ 


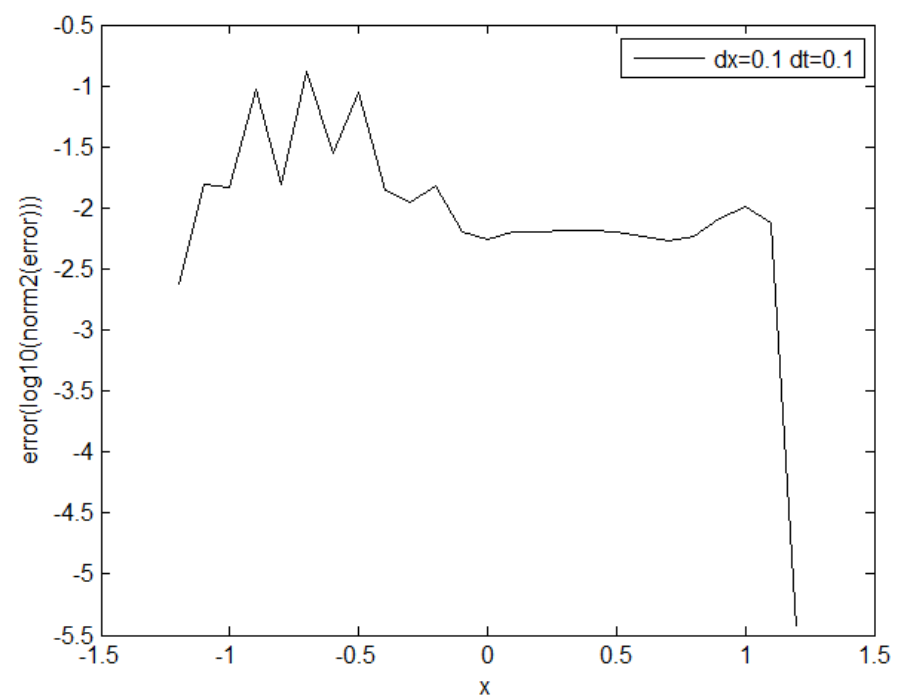

Gambar 6. Nilai $\log _{10} \|$ error $\|_{2}$ terhadap domain ruang untuk EFG-DGM dengan $\Delta x=0,1, \Delta t=0,1$ pada $t=1,0$

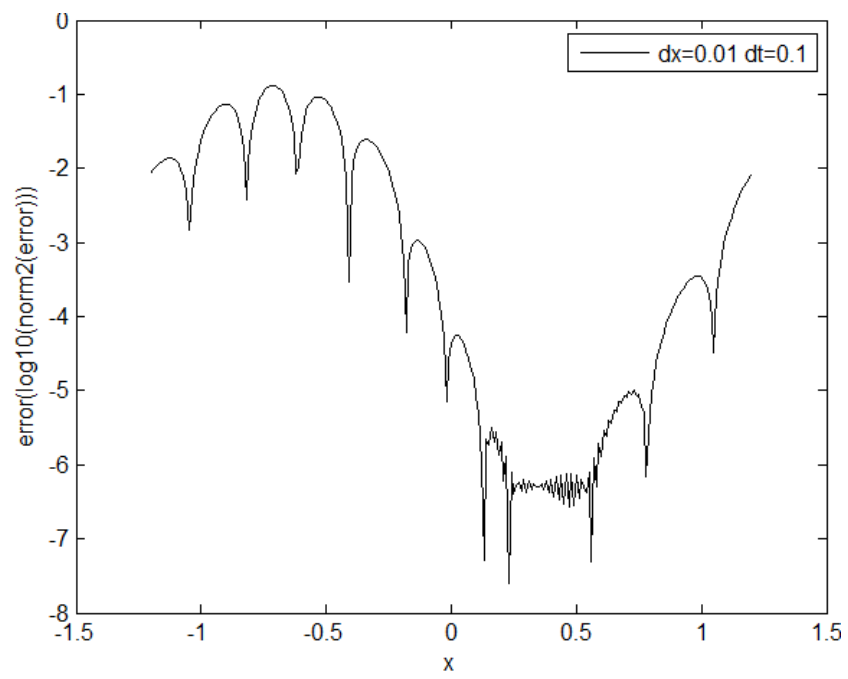

Gambar 7. Nilai $\log _{10} \|$ error $\|_{2}$ terhadap domain ruang untuk EFG-DGM dengan $\Delta x=0,01, \Delta t=0,1$ pada $t=1,0$

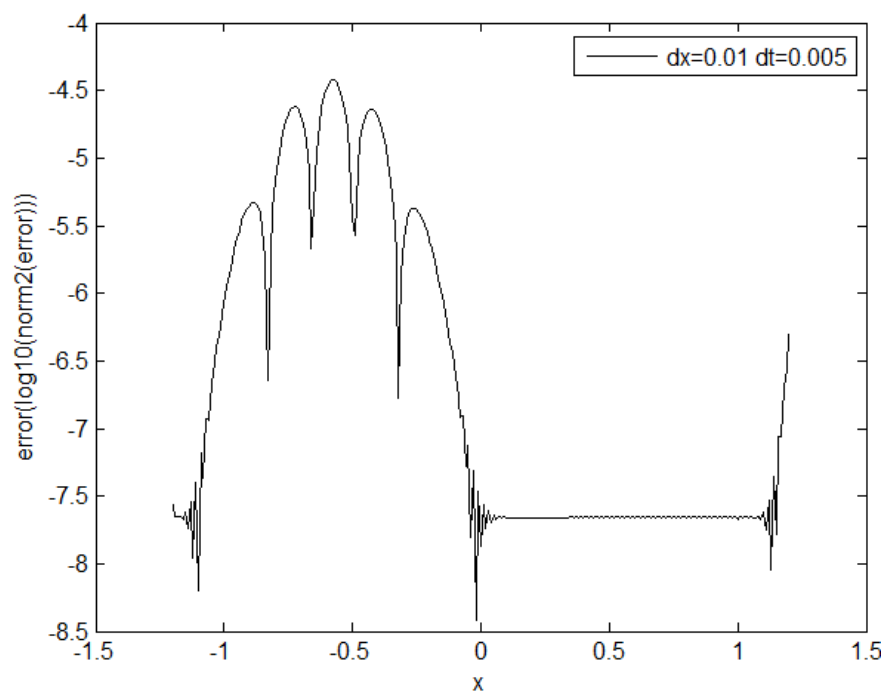

Gambar 8. Nilai $\log _{10} \|$ error $\|_{2}$ terhadap domain ruang untuk EFG-DGM dengan $\Delta x=0,1, \Delta t=0,005$ pada $t=1,0$ 
Untuk mengetahui nilai error dengan berbagai variasi $\Delta x$ dan $\Delta t$ maka dilakukan simulasi dan hasilnya ditampilkan pada Tabel 1 . Pada Tabel 1, menunjukkan bahwa untuk jarak antar node $\Delta x=0,1$ maka variasi pengecilan time increment $\Delta t=0,1,0,01,0,005$ tidak signifikan meningkatkan akurasi dari simulasi, karena $\max$ $\log _{10} \|$ error $\|_{2}$, berkisar pada nilai $-0,8$ dan $-0,9$. Untuk jarak antar node $\Delta x=0,01$, variasi time increment $\Delta t=0,1,0,01,0,005$ meningkatakan akurasi, karena $\max \log _{10} \|$ error $\|_{2}$, dari $-0,8$ untuk $\Delta t=0,1$ berubah menjadi $-3,5$ dan $-4,4$. untuk $\Delta t=0,01$ dan $\Delta t=0,005$. Pada Tabel 1 , ditemui peningkatan akurasi untuk $\Delta x=0,005$ dengan variasi $\Delta t=0,1,0,01,0,005$.

Tabel 1. Hasil $\log _{10} \|$ error $\|_{2}$ untuk berbagai variasi $\Delta x$ dan $\Delta t$

\begin{tabular}{ccc}
\hline $\begin{array}{c}\text { Distance } \\
\text { between } \\
\text { node } \Delta \boldsymbol{x}\end{array}$ & $\begin{array}{c}\text { Time } \\
\text { increment } \Delta \boldsymbol{t}\end{array}$ & $\begin{array}{c}\text { maximum } \\
\log _{\mathbf{1 0}} \| \text { error } \|_{2}\end{array}$ \\
\hline 0,1 & 0,1 & $-0,8887$ \\
0,1 & 0,01 & $-0,8998$ \\
0,1 & 0,005 & $-0,9003$ \\
0,01 & 0,1 & $-0,8844$ \\
0,01 & 0,01 & $-3,577$ \\
0,01 & 0,005 & $-4,425$ \\
0,005 & 0,1 & $-0,8839$ \\
0,005 & 0,01 & $-3,577$ \\
0,005 & 0,005 & $-4,478$ \\
\hline
\end{tabular}

Simulasi time history error untuk $\Delta x=0,1$, ditampilkan Gambar 7, dimana untuk variasi $\Delta t=0,1,0,01,0,005$ hasil error cenderung sama. Pada Gambar 7, $\Delta x=0,1$ time history error pada $\Delta t=0,1,0,01$ berayun dengan rata-rata sama dengan hasil pada $\Delta t=0,005$. Pada $\Delta x=0,1$ variasi dari time increment tidak mempengaruhi akurasi hasil.

Simulasi time history error untuk $\Delta x=0,01$, ditampilkan Gambar 8. Pada $\Delta x=0,01$, variasi $\Delta t$ mempengaruhi akurasi dari error, untuk $\Delta t$ yang lebih kecil menghasilkan nilai error yang lebih kecil. Untuk nilai $\Delta x=0,005$, nilai error ditampilkan pada Gambar 9 variasi $\Delta t$ yang lebih kecil menghasilkan akurasi yang lebih baik. Error yang dihasilkan memiliki kecenderungan mengalami kenaikan terhadap waktu, namun kenaikannya semakin landai.

Pengujian rate of convergence untuk skema EFGDGM dilakukan pada simulasi ini dengan menggunakan dengan complete polynomial orde 1 pada EFG dan untuk DGM menggunakan shape function dengan polynomial orde 1 , dimana untuk $\Delta x=0,005$. Hasil pengujian ditampilkan pada Gambar 12.

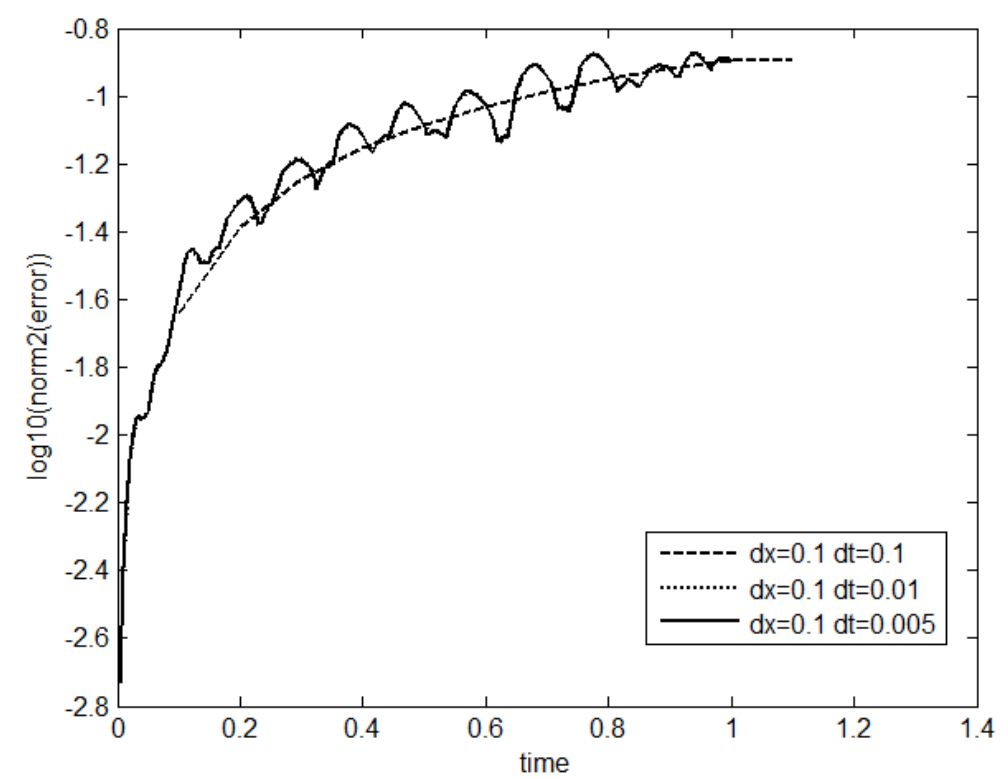

Gambar 9. Time history $\log _{10} \|$ error $\|_{2}$ untuk $\Delta x=0,1$ dengan $\Delta t=0,1 ; 0,01$ dan 0,005 


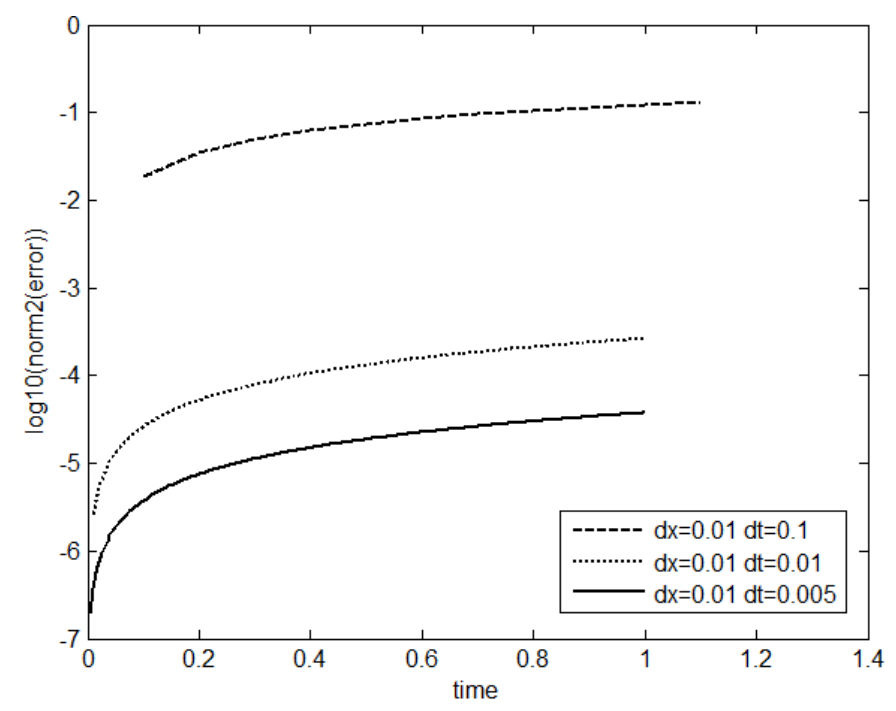

Gambar 10. Time history $\log _{10} \|$ error $\|_{2}$ untuk $\Delta x=0,01$ dengan $\Delta t=0,1 ; 0,01$ dan 0,005

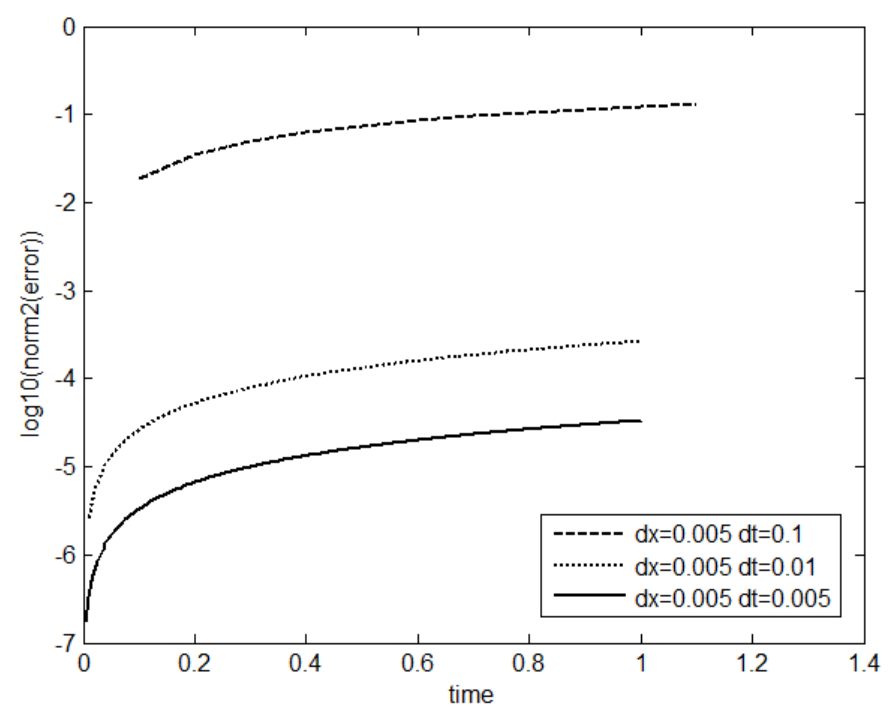

Gambar 11. Time history $\log _{10} \|$ error $\|_{2}$ untuk $\Delta x=0,005$ dengan $\Delta t=0,1 ; 0,01$ dan 0,005

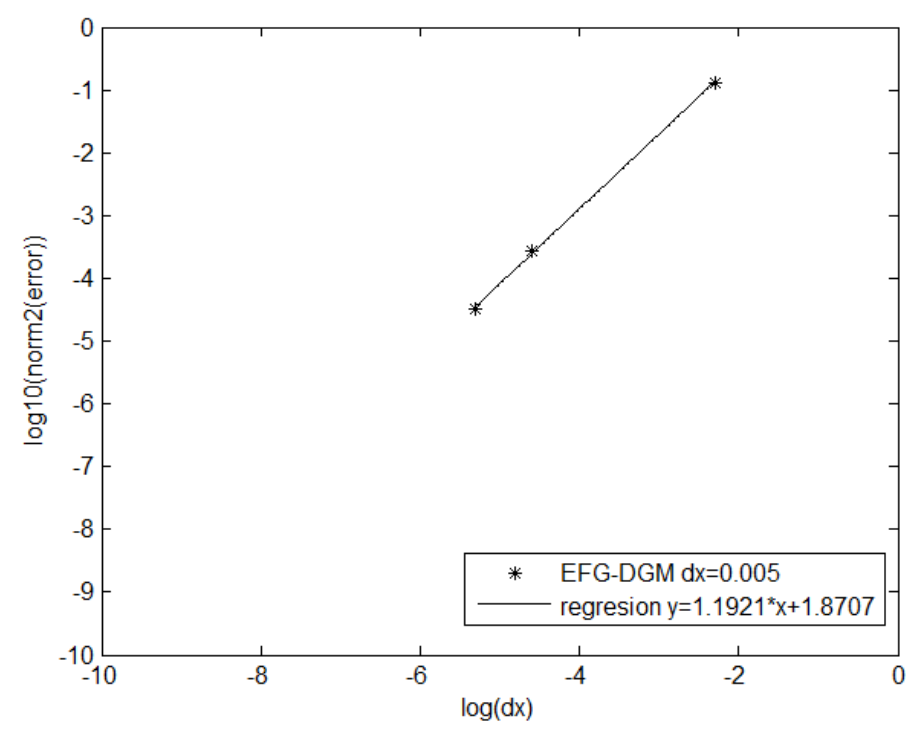

Gambar 12. Laju konvergensi $\log _{10} \|$ error $\|_{2}$ EFG menggunakan complete polynomial orde 1 dan DGM menggunakan polynomial orde 1 


\section{Kesimpulan}

Dari hasil simulasi numerik EFG-DGM untuk EFG complete polynomial orde 1 dan DGM polynomial orde 1 dapat mendekati hasil exact dengan baik. Peningkatan jumlah node atau pengurangan jarak antar node dan pengurangan time increment $\Delta t$ meningkatkan akurasi dengan baik.

\section{Daftar Pustaka}

Li B., Q., 2006. Discontinuous Finite Element in Fluid Dynamics And Heat Transfer, Springer.

Bathe K., J., 1996. Finite Element Procedures, Prentice Hall.
Hesthaven J., S., Warburton T., 2008. Nodal Discontinuous Galerkin Methods: Algorithms, Analysis, and Applications, Springer.

Sarra S., A., Kansa E., J., 2010. Multiquadratic Radial Basis Function Approximation Method for Numerical Solution of Partial Differential Equations, Tech Science Press.

Belytschko T., Liu Y., Y., Gu L., 1994. ElementFree Galerkin Method, Int. J. Num. Meth. Engng. 37:229-256.

Zienkiewicz O., C., Morgan K., 1982. Finite Element and Approximation, John Wiley \& Sons. 